\title{
Educação financeira e decisões financeiras e de consumo dos acadêmicos de um curso de administração
}

\begin{abstract}
RESUMO
O objetivo deste estudo é analisar se existe diferença entre os acadêmicos do curso de Administração da UNIOESTE, Campus Marechal Cândido Rondon - PR, quanto à educação financeira e as decisões financeiras e de consumo. A fundamentação teórica deste estudo foi elaborada descrevendo os conceitos de Educação e Decisão financeira e ainda, uma seção sobre algumas pesquisas já realizadas em relação ao tema. O método utilizado na pesquisa seguiu uma abordagem quantitativa, com coleta de dados através de questionários, caracterizando-a como de levantamento. Referente à classificação, é uma pesquisa descritiva, por relatar, descrever, e comparar dados de uma população específica. Quantos aos resultados, foi possível identificar na presente pesquisa que a família possui um relacionamento positivo fraco com o conhecimento financeiro e que quanto mais conhecimento aprendido na faculdade o indivíduo possui a respeito de finanças, menos propenso ao risco ele está.
\end{abstract}

SLAIRA DienIFER SANTOS*

WANDERSON DUtra GRESELE**

SilvanA ANITA WALTER $* * *$

Palavras-chave: Educação financeira; decisões financeiras; decisões de consumo.

\section{INTRODUÇÃ̃o}

Discussões acerca da necessidade de educação financeira não é recente na área financeira. Entretanto, a crise econômica de 2008, iniciada nos Estados Unidos, acarretou um alto volume de superendividamentos, que foram causados principalmente pelo financiamento de imóveis a pessoas que não tinham como garantir o pagamento desses empréstimos, reforçando assim a necessidade de maiores debates acerca do tema. (DONADIO; CAMPANARIO; RANGEL, 2012).

No Brasil, desde a criação do Plano Real até o ano de 2013 o PIB não teve declínio, o crescimento proporcionou que se estreitasse a relação do dinheiro com as pessoas, pois quanto maior o PIB, alguns facilitadores do endividamento ficam mais latentes: menores juros, facilidade ao acesso de crédito e longos prazos de pagamento, fazendo com que se elevassem os índices de endividamento dos brasileiros (FERNANDES; CANDIDO, 2004).

Atualmente, com um mercado financeiro muito competitivo, a todo o momento são lançados produtos e serviços que facilitam o financiamento das famílias, como por exem-

\footnotetext{
* Unioeste - Campus Marechal Candido Rondon. E-mail: slaira isa15@hotmail.com

** Universidade Estadual do Oeste do Paraná, campus de Marechal Cândido Rondon.

E-mail: wanderson.gresele@hotmail.com .

*** Universidade Estadual do Oeste do Paraná, campus de Marechal Cândido Rondon.

E-mail: silvanaanita.walter@gmail.com .
} 
plo, cartões de crédito, empréstimos, leasing, cheque especial, entre outros, fazendo com que o endividamento aumente de maneira significativa, já que o desejo de consumo e a facilidade de aquisição produtos financeiros estão atrelados. (MARCOLIN; ABRAHAM, 2006; LUCCI et al., 2006).

$\mathrm{Na}$ busca de trazer para a população os fundamentos da educação financeira, no ano de 2010, foi desenvolvido um plano diretor da Estratégia Nacional de Educação Financeira - ENEF em parceria com o Ministério da Educação - MEC, um documento para educação e orientação financeira nas escolas, colocando de forma objetiva as relações com o dinheiro e a leitura de realidade frente as decisões financeiras. O que evidencia a preocupação dos governos com a saúde econômica do país.

Apesar dos esforços e preocupação dos governos com a saúde financeira da população e seu impacto na economia do país, o Sistema de Proteção de Crédito (SPC, 2018), registrou que mais de 63 milhões de brasileiros estão inadimplentes, mostrando que ainda o país necessita de maiores investimento em relação às finanças. Ademais, o órgão de Estratégia Nacional de Educação Financeira - ENEF (2018), constatou que, no geral, o dinheiro que se tem em mãos só serve para o pagamento de dívidas, e os investimentos não vão além de comprar bens, como carro e casa.

Dado sua importância, o endividamento da população é um objeto que vem sendo estudado mundo financeiro com mais afinco, levando esse problema a ser visto de forma mais crítica e ser acompanhado de perto, na busca de solucioná-lo (DONADIO, CAMPANARIO E RANGEL, 2012).

Diante disso, é necessária uma preparação para a tomada de decisão de consumo e financiamento, pois muitos consumidores desprovidos de conhecimento sobre finanças pessoais fazem o nível de endividamento crescer de maneira acelerada (MARCOLIN; ABRAHAM, 2006; LUCCI et al., 2006). Segundo Andrade e Lucena (2016), o conhecimento do mercado financeiro e seus produtos, faz com que as pessoas tomem decisões mais eficazes em suas negociações, compras e investimentos, por permitir que compras impulsivas sejam reduzidas e o planejamento pessoal e familiar seja melhorado, garantindo assim que no final do mês o dinheiro tenha sido suficiente para o pagamento das contas e ainda sobre uma parcela para os investimentos.

Formalizar a educação acerca de finanças é indispensável, pois reflete positivamente na melhora da qualidade de vida e numa redução dos índices de inadimplências, já que escolhas ruins podem gerar altos gastos com juros e taxas (FERNANDES; CANDIDO, 2004).

Dado que, no geral, nos cursos de Administração os alunos cursam as cadeiras relacionadas à área financeira, pode-se questionar: eles não têm dificuldades em tomar decisões em relação a sua vida financeira? Essa pergunta justifica essa pesquisa, pois para Vieira, Bataglia e Sereia (2011), a educação financeira permite, através de uma correta análise das informações, que decisões mais assertivas sejam tomadas e hábitos sejam criados.

Diante do exposto, a pergunta que norteia essa pesquisa é: Há diferenças no nível das tomadas de decisões financeiras e de consumo dos alunos do curso de Administração? Sendo assim, o objetivo desse estudo analisar as diferenças no nível de tomada de 
decisões financeiras e de consumo dos alunos do curso de administração da Universidade Estadual do Oeste do Paraná, UNIOESTE, campus de Marechal Cândido Rondon, Paraná. Esta pesquisa está dividida em seis sessões: sendo a primeira a introdução; a segunda a fundamentação teórica, na qual são explanados conceitos de Educação e Decisão Financeira; a terceira que aborda os métodos empregados na realização da pesquisa; a quarta apresenta a análise dos dados coletados; e na última sessão, as considerações finais do estudo para possíveis novas pesquisas.

\section{FUNDAÇÃMENTAÇão TÉORICA}

\subsection{Educação financeira}

A educação financeira pode ser compreendida sob, no mínimo, dois enfoques. Enquanto para alguns é um conceito vasto que abrange uma compreensão da economia e de como as decisões financeiras são afetadas por condições e circunstâncias econômicas, para outros, a educação financeira é limitada a gestão básica do dinheiro: orçar, poupar e investir (WORTHINGTON, 2006).

Desdobrando os termos, Lucci et al. (2006) coloca o termo "educação" como o conhecimento das definições necessárias para a realização de uma tarefa, e "financeira" é pertinente ao controle monetário das atividades corriqueiras, o qual envolve pagamentos, cartões de crédito, financiamentos, entre outros. Para tanto, Lelis (2006) ressalta que, educação financeira é o conhecimento necessário para a realização da prática das atividades financeiras, valendo destacar que a abrangência dessas informações torna a vida financeira mais simplificada quanto às decisões em relação ao próprio dinheiro.

Como é evidenciado, o termo 'educação financeira' é visto de maneira distinta entre os autores e não há uma definição única. Mas, no geral, pode ser pensado como a capacidade de fazer análises inteligentes e agir com decisões eficazes em relação ao uso do dinheiro (PUNHAGUI; VIEIRA; FAVORETO, 2016).

Outro aspecto importante é que educar a população financeiramente é parte da responsabilidade dos governos, pois promovendo educação financeira, tem-se uma melhora no desenvolvimento econômico geral. Também é importante identificar as classes que mais "sofrem" com a falta de instrução e focalizar, pois, a falta de conhecimento impulsiona o crescimento do número de famílias inadimplentes e a desregulamentação do mercado financeiro (SILVA et al., 2017).

Ainda para Melo (2016), a disseminação dos conteúdos e aprendizagem de educação financeira é de extrema importância em um país como o Brasil, no qual o leque do mercado financeiro é vasto, mas que sua população não possui o aculturamento acerca de finanças.

Utilizar a educação financeira é um método que promove o conhecimento do cenário e dos conceitos do mundo econômico para a melhoria do planejamento e implementação da tomada de decisões, além disso, proporciona o saber de como utilizar ferramentas de captação e multiplicação de capital, evitando o desperdício e alocando os recursos de forma 
adequada, contribuindo assim, para o desenvolvimento econômico (ANDRADE; LUCENA, 2018).

\subsection{Decisões financeiras}

Tomar uma decisão é um processo complexo. Quando uma situação é proposta os indivíduos ficam muito suscetíveis ao erro, isso é comum, pois os fatores emocional, cultural e social influenciam como esse processo vai ser finalizado. Diante das mais diversas situações em que uma decisão deve ser tomada, o esperado é que ela seja realizada de maneira racional e que nos leve a um resultado mais próximo do perfeito, porém quando não se entende como essa situação tramita, aumentam a possibilidade de risco ao erro (BAZERMAN; MOORE, 2014).

As decisões pessoais são tomadas em razão dos valores morais ou utilidade e não em razão de valores monetários, pois os valores monetários estão disponíveis de igual forma para todos, entretanto a utilidade depende de questões particulares de quem deseja tomar a decisão. (ALBERTO, 2014.)

No geral, para tomar uma decisão é necessário abster-se de dados, informações e conhecimento, mas geralmente isso está fragmentado em nosso cérebro e fica disperso, sofrendo influencia também dos modelos mentais de cada indivíduo (ANGELONI, 2003).

As pessoas instruídas formalmente tomam decisões mais apropriadas que os demais que nunca tiveram contato com o tema (PENG et. al., 2007). Do ponto de vista de que alunos do curso de Administração recebem o conteúdo de educação financeira de maneira formal pelo contato e aprendizagem das disciplinas relacionadas à Matemática financeira, eles tendem a tomar decisões mais assertivas na área financeira (LUCCI et al., 2006).

Ainda, com relação a literatura financeira, estudos mostram que os indivíduos vão adquirindo conhecimento ao longo do tempo, pressupondo que o seu cume ocorre na fase adulta, e que com menos idade os conhecimentos ainda não estão totalmente absorvidos e com idade mais avançada a capacidade cognitiva é reduzida, interferindo na tomada de decisões. Contudo, aspectos físicos, psicológicos e de valores sociais também são considerados nas decisões de consumo e investimento (ARRONDEL et. al. 2013).

\subsection{Pesquisas sobre educação financeira}

Esta seção não busca fazer uma revisão da literatura acerca do tema, mas apenas apresentar algumas pesquisas que trata do tema educação financeira no ambiente acadêmico, principalmente na área de gestão.

Em um estudo realizado na Faculdade Independente, Lucci et al. (2006) buscou identificar o perfil dos indivíduos acerca da educação financeira, focalizando em duas variáveis principais: Nível de conhecimento sobre educação financeira e Atitudes dos indivíduos em relação às decisões financeiras, mostrando que o que é apreendido em teoria, em determinadas situações não são postas em prática. Através do método de survey e com os dados coletados com o questionário. O questionário utilizado para a obtenção das res- 
postas contou com questões que abordam os conhecimentos básicos ensinados no curso de Administração, como por exemplo, fluxo de caixa, valor do dinheiro no tempo e custo de risco e oportunidade. Além disso, questões relacionadas ao perfil, influências e decisões de compras e investimentos também o compunham, dado que não só os conteúdos ensinados influenciam o aluno.

Concluiu-se que a qualidade das decisões financeira é influenciada pelos conhecimentos sobre educação financeira formalizada dos indivíduos. Rogers, Favato e Securato (2008), aplicaram questionários em dois grupos distintos de alunos. O primeiro, formado por iniciantes de cursos tecnólogos em uma universidade privada, nas áreas de Recursos Humanos e Marketing, e avaliaram que esse grupo tem baixa instrução financeira. Já o inverso aconteceu com o segundo grupo que era formado por alunos dos últimos semestres da graduação dos cursos de Administração e Ciências contábeis de uma renomada universidade pública, onde notou-se que os conceitos estavam mais sólidos, considerando que o conteúdo acerca de finanças é mais acentuado nesses cursos.

Vieira, Bataglia e Sereia (2011) verificaram que a educação financeira dos alunos do curso de Administração, Ciências Econômicas e Ciências Contábeis de uma universidade do norte do Paraná variam de acordo com o ano da graduação dos estudantes. Utilizando um questionário de pesquisa evidencia-se que alunos do último ano da graduação estão propensos a tomar atitudes mais assertivas em relação às decisões de investimento e consumo.

\section{Metodologia}

Com o objetivo de analisar as diferenças no nível de tomada de decisões financeiras e de consumo dos alunos do curso de administração da Universidade Estadual do Oeste do Paraná, UNIOESTE, campus de Marechal Cândido Rondon, Paraná, a pesquisa adotou uma abordagem quantitativa, haja vista a necessidade de se obter resultados confiáveis, além de se adotar um procedimento de levantamento e quantificação de dados numéricos com o uso de técnicas estatísticas.

Quanto à classificação, está é uma pesquisa descritiva, pois desenvolveu a descrição de características, relatos e comparação de fenômenos, perfil e características de decisões financeiras, de determinada população, no caso, acadêmicos do curso de administração da Universidade Estadual do Oeste do Paraná, UNIOESTE, campus de Marechal Cândido Rondon, Paraná. Ademais, pesquisas descritivas detém caráter transversal, avaliando indivíduos de diferentes faixas etárias em um único momento a fim de obter dados dos efeitos de maturação dos diferentes grupos. (CERVO; BERVIAN, 1983; GIL, 2008; FERNANDES; GOMES, 2009).

\subsection{População}

A população (universo), pode ser definida por um conjunto de elementos que possuem as mesmas características, podendo ser todas elas iguais ou apenas uma em comum (LOPES, L., 2003); na presente pesquisa o universo do estudo são os acadêmicos do curso de Administração da Universidade Estadual do Oeste do Paraná - Campus Marechal Can- 
dido Rondon, na qual, se divide em $1^{\circ}$ ano (46 acadêmicos); $2^{\circ}$ ano (38 acadêmicos); $3^{\circ}$ ano (38 acadêmicos); $4^{\circ}$ ano (17 acadêmicos), totalizando 170 alunos matriculados. Na aplicação da pesquisa, obteve-se 106 acadêmicos respondentes, divididos em $1^{\circ}$ ano (32 acadêmicos); $2^{\circ}$ ano (30 acadêmicos); $3^{\circ}$ ano (27 acadêmicos); $4^{\circ}$ ano (17 acadêmicos).

\subsection{Instrumento De Coleta De Dados}

Neste estudo, o instrumento utilizado para a coleta de dados foi questionário. Ele foi composto de perguntas fechadas, na qual o respondente tem uma opção de escolha entre duas alternativas e por meio de perguntas de múltipla escolha, que diferente das questões fechadas possuem mais que uma alternativa que aborda o mesmo tema (MARCONI; LAKATOS, 2010). Utilizou-se o questionário por ser de fácil e segura aplicação, principalmente por abranger um número maior de pessoas (MARCONI; LAKATOS, 2003, p.201).

Utilizou-se o questionário de LUCCI et al. (2006) que apresenta perguntas sobre conceitos de finanças, nível de conhecimento, perfil do respondente e decisões de consumo e investimento.

O nível de conhecimento sobre educação financeira trata-se de conhecimentos básicos como liquidez de ativos, que decorre de a capacidade dos ativos serem lucrativos (SILVA, 2003); valor do dinheiro no tempo, que é ocasionado pela inflação (NETO, R.; CRUZ, G ANDRICH, G.; 2009); e juros compostos, efeito da incidência de juros compostos no custo de financiamento, fluxo de caixa, orçamento e risco.

Atitude dos indivíduos em relação às decisões financeiras trata das reações dos indivíduos em sua vida prática. Esta variável tem por objetivo avaliar se há outros fatores que influenciam as decisões financeiras e de consumo, ou seja, se apesar dos conhecimentos em finanças, os indivíduos tomam decisões não necessariamente eficientes.

Para identificar o perfil dos acadêmicos foram abordadas quatro questões. Estas questões são importantes porque corroboram para a explicação sobre as atitudes dos entrevistados e seu nível de educação financeira. (LUCCI et al., 2006).

Além, na terceira categoria, três questões foram abordadas acerca das influências financeiras, pois como o conhecimento do respondente não tem relação somente do seu perfil, buscou verificar se família, amigos e o grau de escolaridade de pessoas próximas podem influenciar suas decisões (MAGRO, et al., 2018).

Na última seção de perguntas foram avaliadas as atitudes dos pesquisados, além de conceitos aprendidos no curso, como por exemplo: liquidez, que decorre a capacidade dos ativos serem lucrativos (SILVA, 2003); valor do dinheiro no tempo, que é causado pela inflação e está relacionado com custo de oportunidade; dívidas "roladas", que representam custos financeiros mais elevados; e, por último, se o pesquisado tem a noção de que a antecipação de consumo está associada a um ônus. 


\subsection{Instrumento de análise}

A análise foi realizada a partir do software IBM SPSS Statistics 22, no qual foram calculadas as estatísticas descritivas. As análises foram desenvolvidas utilizando-se da Análise das Correlações. Análise das Correlações, utilizou-se a técnica de Spearman para apresentar correlação das variáveis, mostrando qual dimensão possui maior relacionamento com as variáveis dependentes. (FIELD, 2013).

\section{Apresentação e ANÁlise dos dados}

Nesta seção são apresentadas as análises dos dados coletados, aonde busca-se identificar o perfil dos respondentes, a quantidade de erros e acertos das questões propostas por ano. Ademais, são analisadas as atitudes financeiras e de consumo dos respondentes e a correlação das suas influências financeiras com suas atitudes.

\subsection{Perfil dos respondentes}

As tabelas a seguir apresentam os dados do perfil dos respondentes, mostrando o ano de curso, sexo, faixa etária, estado civil e fonte de renda. Tal como indica Lucci et al. (2006), estas questões são importantes porque corroboram para a explicação sobre as atitudes dos entrevistados e seu nível de educação financeira. Em primeiro,

os dados da tabela 1, apresentam a idade dos acadêmicos do curso, identificação das classes da idade foi desenvolvida por meio da análise dos quartis.

Tabela1 - Idade

\begin{tabular}{ccc}
\hline Idade & Total & Porcentagem \\
De 17 a 19 anos & 45 & $42,00 \%$ \\
20 anos & 15 & $14 \%$ \\
De 21 a 22 anos & 21 & $20 \%$ \\
De 23 a 52 anos & 25 & $24 \%$ \\
\hline Total & $\mathbf{1 0 6}$ & $\mathbf{1 0 0 \%}$ \\
\hline
\end{tabular}

Fonte: Dados da pesquisa (2019).

Observa-se que a idade dos alunos que cursam administração varia de 17 a 52 anos, tendo a maior concentração de alunos com idade de 17 a 19 anos, ocupando 42\% de um total de 106 alunos.

A Tabela 2 apresenta a divisão dos alunos por sexo e ano de curso. 
Tabela2 - Sexo

\begin{tabular}{cccc}
\hline \multirow{2}{*}{ Ano da faculdade } & \multicolumn{2}{c}{ Sexo } & Total \\
\cline { 2 - 3 } Primeiro Ano & Masculino & Feminino & \\
Segundo Ano & 17 & 15 & $\mathbf{3 2}$ \\
Terceiro Ano & 11 & 19 & $\mathbf{3 0}$ \\
Quarto Ano & 15 & 12 & $\mathbf{2 7}$ \\
Total & 6 & 11 & $\mathbf{1 7}$ \\
\hline
\end{tabular}

Fonte: Dados da pesquisa (2019).

A Tabela 2 evidencia que o maior número de alunos se encontra no primeiro ano e vai decrescendo até o quarto ano. Dos 106 entrevistados, o maior número é do sexo feminino (57) e se concentra em maior parte no segundo ano.

Os dados da Tabela 3 apresentam o estado civil dos acadêmicos divididos pelo ano do curso.

Tabela 3 - Estado civil

\begin{tabular}{cccccc}
\hline \multirow{2}{*}{ Ano da faculdade } & \multicolumn{4}{c}{ Estado Civil } & \multirow{2}{*}{ Total } \\
\cline { 2 - 5 } & Solteiro & Casado & Viúvo & Separado & \\
Primeiro Ano & 31 & 1 & 0 & 0 & $\mathbf{3 2}$ \\
Segundo Ano & 25 & 3 & 0 & 2 & $\mathbf{3 0}$ \\
Terceiro Ano & 23 & 4 & 0 & 0 & $\mathbf{2 7}$ \\
Quarto Ano & 11 & 5 & 1 & 0 & $\mathbf{1 7}$ \\
\hline Total & $\mathbf{9 0}$ & $\mathbf{1 3}$ & $\mathbf{1}$ & $\mathbf{2}$ & $\mathbf{1 0 6}$ \\
\hline
\end{tabular}

Fonte: Dados da pesquisa (2019).

A maior parte dos acadêmicos (85\%) se encontram solteiros, destes, proporcionalmente a maioria no primeiro com decrescimento até o quarto ano.

A maior parte dos acadêmicos de administração exerce atividade remunerada em período integral, sendo a maioria alunos do segundo ano. Dos que não exercem, a maioria são alunos do primeiro ano.

A Tabela 4 apresenta se os acadêmicos exercem atividade remunerada, e se sim, qual o período. 
Tabela 4 - Atividade remunerada

\begin{tabular}{ccccc}
\hline \multirow{2}{*}{ Ano da faculdade } & \multirow{2}{*}{ Não } & \multicolumn{2}{c}{ Atividade remunerada } & \multirow{2}{*}{ Total } \\
\cline { 3 - 5 } & & Sim, meio período & Sim, período integral & \\
\hline Primeiro Ano & 6 & 7 & 19 & $\mathbf{3 2}$ \\
\hline Segundo Ano & 3 & 4 & 23 & $\mathbf{3 0}$ \\
\hline Terceiro Ano & 3 & 5 & 19 & $\mathbf{2 7}$ \\
\hline Quarto Ano & 1 & 0 & 16 & $\mathbf{1 7}$ \\
\hline Total & $\mathbf{1 3}$ & $\mathbf{1 6}$ & $\mathbf{7 7}$ & $\mathbf{1 0 6}$ \\
\hline
\end{tabular}

Fonte: Dados da pesquisa (2019)

Apresenta os dados de fonte de renda dos acadêmicos, a Tabela 5.

Tabela 5 - Fonte de renda

\begin{tabular}{ccccccc}
\hline Ano da faculdade & & Formal & Informal & Outros & Total \\
Primeiro Ano & 22 & 5 & 5 & $\mathbf{3 2}$ & & \\
Segundo Ano & 26 & 1 & 3 & $\mathbf{3 0}$ & & \\
Terceiro Ano & 23 & 2 & 2 & $\mathbf{2 7}$ & & \\
Quarto Ano & & 15 & & 1 & 1 & $\mathbf{1 7}$ \\
Total & & $\mathbf{8 6}$ & & $\mathbf{9}$ & $\mathbf{1 1}$ & $\mathbf{1 0 6}$ \\
\hline
\end{tabular}

Fonte: Dados da pesquisa (2019).

Embora mais de $10 \%$ dos respondentes não exerce atividade remunerada, ainda assim há uma fonte de renda. Conforme a Tabela 5, 11 dos respondentes obtém suas receitas sem ser por meio de emprego formal o informal, podendo ser mesada ou outros tipos de recompensas, porém, o principal meio de obtenção de renda da maioria dos estudantes é o emprego formal.

Os dados Da Tabela 6 demostra a renda pessoal dos acadêmicos de acordo com o ano de curso.

Tabela 6 - Renda mensal pessoal

\begin{tabular}{|c|c|c|c|c|c|c|}
\hline $\begin{array}{c}\text { Ano da } \\
\text { faculdade }\end{array}$ & $\begin{array}{l}\text { Até RS } \\
900,00\end{array}$ & $\begin{array}{c}\text { De } 900,01 \\
\text { até } R \$ \\
2000,00\end{array}$ & $\begin{array}{c}\text { De } 2000,01 \text { até } \\
\text { R\$ 3000,00 }\end{array}$ & $\begin{array}{c}\text { De } 3000,01 \text { até } \\
\text { R\$ 4000,00 }\end{array}$ & $\begin{array}{c}\text { Acima de } \\
\text { R\$ 4000,00 }\end{array}$ & Total \\
\hline Primeiro & 16 & 14 & 0 & 0 & 2 & 32 \\
\hline Segundo & 6 & 19 & 3 & 1 & 1 & 30 \\
\hline Terceiro & 4 & 17 & 6 & 0 & 0 & 27 \\
\hline Quarto & 1 & 5 & 5 & 6 & 0 & 17 \\
\hline Total & 27 & 55 & 14 & 7 & 3 & 106 \\
\hline
\end{tabular}


Os dados coletados evidenciam que 55 dos alunos tem renda mensal variando de R \$ 900,01 até R\$ 2000,00. Neste ranking, a aglomeração maior é ocupada pelos alunos do segundo ano, em sequência, alunos do terceiro, e por fim, primeiro e quarto. Nota-se que os alunos que possuem menor renda estão cursando o primeiro ano do curso, e que dos alunos do quarto ano a maioria tem sua renda variando de $\mathrm{R} \$ 900,01$ até $\mathrm{R} \$ 4000,00$.

A próxima Tabela, assim como a tabela anterior, também busca mensurar a renda dos questionados, no entanto, agora se trata da renda mensal familiar dos acadêmicos.

Tabela 7 - Renda mensal familiar

\begin{tabular}{|c|c|c|c|c|c|c|}
\hline \multicolumn{7}{|c|}{ Renda mensal familiar } \\
\hline $\begin{array}{c}\text { Ano da facul- } \\
\text { dade }\end{array}$ & $\begin{array}{l}\text { Até R\$ } \\
2000,00\end{array}$ & $\begin{array}{l}\text { De } R \$ 2000,01 \\
\text { até } R \$ 4000,00\end{array}$ & $\begin{array}{l}\text { De } R \$ 4000,00 \\
\text { até } R \$ 6000,00\end{array}$ & $\begin{array}{l}\text { De } R \$ 6000,01 \\
\text { até } R \$ 8000,00\end{array}$ & $\begin{array}{c}\text { Acima } \\
\text { de R\$ } \\
8000,00\end{array}$ & Total \\
\hline Primeiro & 4 & 13 & 7 & 4 & 4 & 32 \\
\hline Segundo & 1 & 10 & 12 & 3 & 4 & 30 \\
\hline Terceiro & 3 & 7 & 9 & 5 & 3 & 27 \\
\hline Quarto & 2 & 4 & 5 & 4 & 2 & 17 \\
\hline Total & 10 & 34 & 33 & 16 & 13 & 106 \\
\hline
\end{tabular}

Fonte: Dados da pesquisa (2019).

A tabela 5 evidencia que as maiores médias dos ganhos familiares mensais dos alunos variam de $\mathrm{R} \$ 2.000,00$ até $\mathrm{R} \$ 6.000,00$. Destes, os alunos que estão no segundo ano são os que ocupam o maior número, em sequência com a diferença de dois acadêmicos a menos, o primeiro ano, em seguida, o terceiro e por fim o quarto, já que é o ano em que a concentração de alunos é menor (17).

O tipo de dívida que os acadêmicos possuem foi analisada na Tabela 8.

Tabela 8 - Tipo de dívidas

\begin{tabular}{c|c|c|c|c|c}
\hline \multicolumn{7}{c}{$\begin{array}{c}\text { Tipo de dívidas } \\
\text { faculdade }\end{array}$} & $\begin{array}{c}\text { Sim, contas } \\
\text { de longo } \\
\text { prazo }\end{array}$ & $\begin{array}{c}\text { Sim, mas não } \\
\text { faz ideia de } \\
\text { como pagar }\end{array}$ & $\begin{array}{c}\text { Sim, e vai pagar } \\
\text { em pouco tempo }\end{array}$ & Não possui & $\begin{array}{c}\text { Total de } \\
\text { respon- } \\
\text { dentes }\end{array}$ \\
\hline Primeiro Ano & 7 & 1 & 6 & 18 & $\mathbf{3 2}$ \\
\hline Segundo Ano & 9 & 0 & 8 & 13 & $\mathbf{3 0}$ \\
\hline Terceiro Ano & 4 & 0 & 11 & 12 & $\mathbf{2 7}$ \\
\hline Quarto Ano & 6 & 1 & 5 & 5 & $\mathbf{1 7}$ \\
\hline Total & $\mathbf{2 6}$ & $\mathbf{2}$ & $\mathbf{3 0}$ & $\mathbf{4 8}$ & $\mathbf{1 0 6}$ \\
\hline$\%$ & $\mathbf{2 5 \%}$ & $\mathbf{2 \%}$ & $\mathbf{2 8 \%}$ & $\mathbf{4 5 \%}$ & $\mathbf{1 0 0 \%}$ \\
\hline
\end{tabular}

Fonte: Dados da pesquisa (2019). 
De acordo com a questão 10 , quase $50 \%$ dos alunos não possuem dividas. Dos que possuem, $25 \%$ estão pagando financiamentos de longo prazo e $28 \%$ sabe exatamente quando as dívidas serão quitadas e apenas $2 \%$ estão endividados de forma que não sabem o que irão fazer para quitá-las.

Em síntese, pode-se destacar que a maioria dos acadêmicos de Administração da UNIOESTE - Campus Marechal Cândido Rondon são do sexo feminino, tem idade média de 19 anos, e tem renda média pessoal até R\$2000,00. Nota-se que o curso inicia com a maior quantidade de alunos no primeiro ano, e depois vai decrescendo a quantidade. Ademais, destaca-se que menos de $50 \%$ dos acadêmicos não possuem dívidas.

\subsection{Conhecimento sobre educação financeira}

Esta sessão aborda a quantidade de erros e acertos dos pesquisados quanto aos seus conhecimentos em relação ao ano do curso. O nível de conhecimento sobre educação financeira trata-se de conhecimentos básicos como liquidez de ativos, que decorre de a capacidade dos ativos serem lucrativos; valor do dinheiro no tempo, que é ocasionado pela inflação; e juros compostos, efeito da incidência de juros compostos no custo de financiamento, fluxo de caixa, orçamento e risco (SILVA, 2003; NETO, R.; CRUZ, G ANDRICH, G.; 2009).

A questão 21 aborda o conhecimento dos alunos em relação a valor do dinheiro no tempo, na qual, dentre três alternativas o respondente deveria assinalar a alternativa em que o rendimento do investimento seria maior.

Tabela 9 - Conhecimento sobre o valor do dinheiro no tempo

\begin{tabular}{cccccc}
\hline Ano da faculdade & A & B & C & $\begin{array}{c}\text { Total de respon- } \\
\text { dentes }\end{array}$ & \% de acertos \\
\hline Primeiro Ano & 6 & 2 & 24 & $\mathbf{3 2}$ & $\mathbf{7 5 \%}$ \\
Segundo Ano & 8 & 2 & 20 & $\mathbf{3 0}$ & $\mathbf{6 7 \%}$ \\
Terceiro Ano & 4 & 1 & 22 & $\mathbf{2 7}$ & $\mathbf{8 1 \%}$ \\
Quarto Ano & 5 & 2 & 10 & $\mathbf{1 7}$ & $\mathbf{5 9 \%}$ \\
\hline Total & $\mathbf{2 3}$ & $\mathbf{7}$ & $\mathbf{7 6}$ & $\mathbf{1 0 6}$ & $\mathbf{7 2 \%}$ \\
\hline
\end{tabular}

Fonte: Dados da pesquisa (2019).

Foram $72 \%$ dos respondentes que acertaram a questão marcando a alternativa " $\mathrm{C}$ " que evidenciava que o dinheiro de Daniela rendeu mais por estar guardado a juros compostos. A maior parte dos acertos ficou em responsabilidade dos acadêmicos do terceiro ano com $81 \%$, e o menor índice de acertou foi registrando no quarto ano, cujo somente 59\% deles marcaram a alternativa correta.

O conhecimento sobre liquidez dos ativos foi medido pela questão 19, na qual pedia qual dos ativos eram menos vantajosos em caso de uma reserva de emergência, tal qual era marcado pela alternativa $\mathrm{D}$. 
Tabela 10 - Conhecimento sobre liquidez

\begin{tabular}{c|c|c|c|c|c|c}
\hline Ano da faculdade & A & B & C & D & $\begin{array}{c}\text { Total de res- } \\
\text { pondentes }\end{array}$ & \% de acerto \\
\hline Primeiro Ano & 6 & 9 & 5 & 12 & $\mathbf{3 2}$ & $\mathbf{3 8 \%}$ \\
\hline Segundo Ano & 7 & 6 & 4 & 13 & $\mathbf{3 0}$ & $\mathbf{4 3 \%}$ \\
\hline Terceiro Ano & 2 & 5 & 2 & 18 & $\mathbf{2 7}$ & $\mathbf{6 7 \%}$ \\
\hline Quarto Ano & 3 & 4 & 1 & 9 & $\mathbf{1 7}$ & $\mathbf{5 3 \%}$ \\
Total & $\mathbf{1 8}$ & $\mathbf{2 4}$ & $\mathbf{1 2}$ & $\mathbf{5 2}$ & $\mathbf{1 0 6}$ & $\mathbf{4 9 \%}$ \\
\hline
\end{tabular}

Fonte: Dados da pesquisa (2019).

Marcaram a alternativa correta quase $50 \%$ dos respondentes, sendo o maior número de acertos pelos alunos do terceiro ano e o menor, marcado pelos alunos do primeiro ano.

O conhecimento dos alunos sobre o custo das dívidas no tempo foi analisado pela questão 23.

Tabela 11 - Conhecimento sobre custos das dívidas

\begin{tabular}{c|c|c|c|c|c|c}
\hline Ano da faculdade & A & B & C & D & $\begin{array}{c}\text { Total de res- } \\
\text { pondentes }\end{array}$ & \% de acerto \\
\hline Primeiro Ano & 7 & 6 & 4 & 15 & $\mathbf{3 2}$ & $\mathbf{4 7 \%}$ \\
\hline Segundo Ano & 7 & 3 & 4 & 16 & $\mathbf{3 0}$ & $\mathbf{5 3 \%}$ \\
\hline Terceiro Ano & 6 & 4 & 0 & 17 & $\mathbf{2 7}$ & $\mathbf{6 3 \%}$ \\
\hline Quarto Ano & 3 & 3 & 1 & 10 & $\mathbf{1 7}$ & $\mathbf{5 9 \%}$ \\
Total & $\mathbf{2 3}$ & $\mathbf{1 6}$ & $\mathbf{9}$ & $\mathbf{5 8}$ & $\mathbf{1 0 6}$ & $\mathbf{5 5 \%}$ \\
\hline
\end{tabular}

Fonte: Dados da pesquisa (2019).

Mais da metade, $55 \%$ dos acadêmicos acertaram a questão marcando a alternativa $\mathrm{D}$, aonde evidencia que quem paga sempre o mínimo da fatura do cartão de crédito paga mais. Os maiores acertos foram dos alunos do terceiro ano, no qual, mais de $60 \%$ da turma acertou. Na sequência, o quarto ano com $59 \%$ de acertos. No entanto, na seguinte questão quase $100 \%$ dos alunos responderam que não tomariam essa atitude, de pagar o valor mínimo.

Com intuito de aferir o conhecimento dos alunos sobre custo de antecipação de consumo, a questão 25 apresentou duas opções de resposta, na qual a primeira era a alternativa correta, dizendo que um financiamento era menos vantajoso do que poupar o mesmo valor por quinze meses. 
Tabela 12 - Conhecimento sobre custo de antecipação de consumo

\begin{tabular}{ccccc}
\hline Ano da faculdade & A & B & Total de respondentes & \% de acerto \\
\hline Primeiro Ano & 22 & 10 & $\mathbf{3 2}$ & $\mathbf{6 9 \%}$ \\
Segundo Ano & 16 & 14 & $\mathbf{3 0}$ & $\mathbf{5 3 \%}$ \\
Terceiro Ano & 17 & 10 & $\mathbf{2 7}$ & $\mathbf{6 3 \%}$ \\
Quarto Ano & 8 & 9 & $\mathbf{1 7}$ & $\mathbf{4 7 \%}$ \\
\hline Total & $\mathbf{6 3}$ & $\mathbf{4 3}$ & $\mathbf{1 0 6}$ & $\mathbf{5 9 \%}$
\end{tabular}

Do total, 59\% dos alunos marcaram a alternativa correta, sendo a maioria, alunos do primeiro ano. O maior número de erros ficou em responsabilidade dos alunos do quarto ano.

Os respondentes ainda tinham que dizer, qual seria a atitude tomada por eles em uma situação igual. De acordo com o resultado, mesmo respondendo que o maior custo seria para Dirceu que escolheu financiar, 9\% fariam a mesma coisa. Em contrapartida 60\% não tomariam essa atitude e o restante ficaria no meio termo, pagando parte do bem a vista e financiando metade.

A questão 27 buscou identificar o conhecimento dos alunos acerca de planejamento financeiro e poupança. Tal questão tinha como resposta certa a alternativa B.

Tabela 13 - Conhecimento sobre planejamento financeiro e poupança

\begin{tabular}{ccccccc}
\hline Ano da faculdade & A & B & C & D & $\begin{array}{c}\text { Total de } \\
\text { respondentes }\end{array}$ & \% de acerto \\
Primeiro Ano & 0 & 19 & 7 & 6 & 32 & $\mathbf{5 9 \%}$ \\
Segundo Ano & 2 & 25 & 2 & 1 & 30 & $\mathbf{8 3 \%}$ \\
Terceiro Ano & 2 & 19 & 4 & 2 & 27 & $\mathbf{7 0 \%}$ \\
Quarto Ano & 0 & 13 & 0 & 3 & 17 & $\mathbf{7 6 \%}$ \\
\hline Total & $\mathbf{4}$ & $\mathbf{7 6}$ & $\mathbf{1 3}$ & $\mathbf{1 2}$ & $\mathbf{1 0 6}$ & $\mathbf{7 2 \%}$ \\
\hline
\end{tabular}

Fonte: Dados da pesquisa (2019).

Marcada por $72 \%$ dos respondentes, a alternativa B, destacou que para José o prazo necessário para juntar dinheiro e comprar uma TV de 800,00 era de 4 meses.

Das questões totais, a média de acerto dos respondentes é $61 \%$. A diferença entre os acertos por ano de curso tem uma variação baixa, no entanto a maior média de acertos é dada pelos alunos do terceiro ano (69\%), os demais ficam em: $1^{\circ}$ ano $(58 \%) ; 2^{\circ}$ ano (60\%); e $4^{\circ}$ ano $(59 \%)$. No geral, o maior número de acertos foi obtido pelos alunos do terceiro ano, que nesta situação já tiveram em sua grade curricular todos os conteúdos abordados. Os alunos do quarto ano foram destaque negativo nas questões acerca de antecipação de consumo e valor do dinheiro no tempo, sendo superado por alunos do primeiro ano. 


\subsection{Atitudes financeiras}

Seguindo Lucci et al. (2006), nesta seção busca-se identificar a atitude de cada pessoa em relação às decisões financeiras, ou seja, as reações dos indivíduos em sua vida prática, com o objetivo avaliar se há outros fatores que influenciam as decisões financeiras e de consumo, ou seja, se apesar dos conhecimentos em finanças, os indivíduos tomam decisões não necessariamente eficientes.

Uma questão buscou identificar o investimento preferível para o entrevistado. Foi possível identificar que $22 \%$ estão mais propensos ao risco e investiriam em ações; $31 \%$ investiriam em fundos de investimento de risco médio; o maior percentual das respostas, $35 \%$, indicaram que o investimento preferível seria poupança, devido a segurança trazida e pelo rendimento; ainda, houve $12 \%$ de entrevistados que investiriam em bens, informando que a segurança em relação ao investimento, já que o bem adquirido é fixo.

Num cruzamento das respostas, revelou-se que as pessoas do sexo feminino são as que mais guardam dinheiro na poupança, e o investimento em ações é predominado pelo sexo masculino e com idade entre 18 até 22 anos.

Além, constatou-se que os alunos que estão mais propensos a risco (33\%) são os que possuem dívidas, mas tem tudo anotado como vai pagar e são solteiros. E dos não endividados, $70 \%$ investiriam ou em fundos de investimento ou poupança.

Quando questionados sobre a aposentadoria, os resultados obtidos identifica que $42 \%$ dos alunos não estão preocupados com a aposentadoria ainda, no entanto, $33 \%$ já possuem um plano para previdência. Coincidentemente, $35 \%$ dos que já possuem planos para isso não estão endividados, são do sexo feminino e tem entre 19 e 23 anos, e $23 \%$ não se preocupa com isso ainda. Em relação aos endividados, $60 \%$ possuem um plano para previdência já efetivo.

Sobre a atitude em relação a dívidas com cartão de crédito, mostra que do total de acadêmicos questionados, $79 \%$ não possuem dívida e pagam todas as faturas no vencimento, enquanto $6 \%$ pagam somente o mínimo. Os respondentes de menos idade, são a maioria quanto a pagar a fatura total.

Já quanto a atitude em adquirir bens, os alunos do curso de administração estão mais propensos a poupar para adquirir um bem a vista, sem financiar, cerca de $55 \%$, estes sendo a maioria que não possuem dividas e tem idade prevalecente de 18 a 21 anos. Além, $41 \%$ ficam no meio termo, ou seja, poupando para a entrada e financiando o restante e apenas $4 \%$ preferem ter o carro imediatamente, financiando todo valor.

Percebe-se, de acordo com as respostas, que não há um padrão nas atitudes dos respondentes, no entanto fica claro que as pessoas do sexo masculino estão mais propensas ao risco e as mulheres a segurança, não sofrendo influência do fator idade. A pesquisa desenvolvida por Schumacher, Gresele e Walter (2018) verificou também que uma correlação significativa da variável endividamento e inadimplência com o atributo sexo, indicando também que mulheres são menos propensas ao endividamento e inadimplência. 


\subsection{Relação do nível de educação e atitude financeira com o ano da faculdade}

A fim de identificar se há uma correlação entre o ano da faculdade e as atitudes dos pesquisados, para tal utilizou-se o teste de correlação de Spearman. A tabela 14 apresenta as correlações entre o ano dos acadêmicos e suas atitudes financeiras.

Tabela 14 - Correlação do ano da faculdade com as atitudes financeiras

\begin{tabular}{cc}
\hline Atitudes financeiras & Ano da faculdade \\
\hline Atitude sobre reserva de emergência & $0,217^{*}$ \\
Atitude quanto a dívidas no cartão de crédito & 0,178 \\
Atitude em relação a financiamentos & $-0,153$ \\
Atitude quanto a aposentadoria & 0,022 \\
Atitude de investimento & $-0,218^{*}$ \\
\hline
\end{tabular}

*A correlação é significativa no nível 0,05 (2 extremidades).

Fonte: Dados da pesquisa (2019).

Constatou-se que a única correlação positiva dos anos com as decisões financeira foi a questão de número 28 , que tratava de quais tipos de recursos seriam melhores em caso de desemprego, que no caso, era marcado pela alternativa A (conta corrente), já que as outras alternativas eram investimentos de baixa liquidez. Foi possível identificar uma correlação negativa na questão 20 , que diz que quanto maior o ano da graduação que o acadêmico se encontra, menor as chances de ele fazer investimentos de alto risco.

Buscou-se também de identificar se o ano da faculdade tem relação com o nível de educação financeira, a Tabela 15 obtida com o teste de correlação de Spearman, mostra os seguintes resultados:

Tabela 15 - Correlação do nível de educação financeira com o ano da faculdade

\begin{tabular}{cc}
\hline & Ano da faculdade \\
\hline Nível de Conhecimento em Educação Financeira & 0,106 \\
\hline
\end{tabular}

Fonte: Dados da pesquisa (2019).

Não foi identificada correlação do ano do curso dos acadêmicos com o seu nível de conhecimento em educação financeira. Portanto, buscou-se identificar outros relacionamentos com o nível de educação financeira. 
Visto que o nível de conhecimento financeiro é construído de diversos tipos de influências, a Tabela 16, buscou identificar qual das influências financeiras se correlacionam com o nível de educação.

Tabela 16 - Correlação do nível de conhecimento com as influências financeiras

\begin{tabular}{cc}
\hline Importância & Nível de Conhecimento \\
\hline Importância da família & $0,349^{* *}$ \\
Importância dos amigos & $-0,128$ \\
Importância da universidade & 0,181 \\
Importância dos livros, revistas, TV e rádio & $-0,048$ \\
Importância da experiência prática financeira & $-0,097$ \\
\hline
\end{tabular}

**A correlação é significativa no nível 0,01 (2 extremidades).

Fonte: Dados da pesquisa (2019).

A única variável significativa de forma positiva para o nível de conhecimento sobre educação financeira, foi a família, o que quer dizer que, embora haja tantas fontes de aquisição de conhecimento, a família é a que mais influencia o conhecimento financeiro.

Lucci et al. (2006) indicam que como os alunos do curso de Administração recebem o conteúdo de educação financeira de maneira formal pelo contato e aprendizagem das disciplinas, eles tendem a tomar decisões mais assertivas na área financeira. Adicionalmente, Vieira, Bataglia e Sereia (2011) verificaram que a os alunos do último ano dos cursos de graduação questionados estão propensos a tomar atitudes mais assertivas em relação às decisões de investimento e consumo. Entretanto, a presente pesquisa não constatou relação entre o nível de conhecimento financeiro com o ano do curso do acadêmico, mas contatou correlação positiva na atitude sobre reserva de emergência e sobre investimos.

Ademais, Arrondel et al., (2013) indicam que outros fatores aspectos físicos, psicológicos e de valores sociais também são influenciadores nas decisões de consumo e investimento. Neste caminho a presente pesquisa verificou correlação da família com o nível de conhecimento financeiro dos acadêmicos.

\section{CONSIDERAÇÕes FINAIS}

É fato que o endividamento da população é um objeto que vem sendo estudado no mundo financeiro, na busca de um olhar mais crítico e possíveis soluções (DONADIO; CAMPANARIO; RANGEL, 2012). Pesquisas indicam que é necessária uma preparação para a tomada de decisão de consumo e financiamento, pois muitos consumidores parecem estar desprovidos de conhecimento (MARCOLIN; ABRAHAM, 2006; LUCCI et al., 2006).

Assim a presente pesquisa teve como objetivo analisar se existe diferença entre os acadêmicos do curso de Administração da UNIOESTE, Campus Marechal Cândido Rondon - PR, quanto à educação financeira e as decisões financeiras e de consumo. Buscou-se então 
destacar os conceitos sobre Educação e Decisão financeira. Quanto ao método, utilizou-se de abordagem quantitativa, com estratégia de pesquisa de levantamento, natureza descritiva, e com coleta de dados através de questionário, disponibilizado por Lucci et al. (2006).

Os resultados obtidos com a análise dos dados apontam que não há uma relação dos conhecimentos dos alunos em relação ao ano do curso, mas sim da família em que foi criado. Esses resultados são diferentes do que os apresentados por Rogers, Favato e Securato (2008) pois neste estudo os resultados apresentaram que quanto maior a formalização nos conhecimentos de educação financeira, mais as atitudes em relação a isso serão assertivas.

No geral, pode-se dizer que que os alunos sabem quais atitudes são mais adequadas. No exemplo da questão acerca de previdência, a maior parte dos respondentes evidenciaram que não se preocupam com isso ainda, no entanto, sabem da importância em que tem de fazer um plano para a aposentadoria. Os alunos conhecem também que há diferença do valor do dinheiro no tempo e a relação disso com a dívida no cartão de crédito. Assim como apresentado por Vieira, Bataglia e Sereia (2011), os acadêmicos que já estão nos últimos anos do curso já possuem um conhecimento mais sólido, portanto tem mais acertos em suas atitudes.

Verificou-se também que as pessoas do sexo masculino estão mais propensas ao risco e as mulheres a segurança os que são mais endividados se estão mais abertos ao risco, e os que menos possuem dividas, são os que guardam seu dinheiro na poupança e tem preferência por investimentos, menos arriscados.

Por fim, embora haja uma correlação entre as variáveis família e conhecimento, não se sabe ao certo o que a família ensinou aos entrevistados, não permitindo uma análise mais concreta. Os resultados expostos são incipiente e servirão de base para outras análises, dos quais focalizarão em detectar a qualidade dos ensinos da família e sua relação com o que é aprendido na universidade.

\section{REFERÊNCIAS}

ALBERTO, G.S. Evidencias das Influências dos Tipos Psicológicos no Comportamento dos Tomadores de Decisões Financeiras. 2014. Dissertação em (Mestrado em Administração) - Pontifícia Universidade Católica. São Paulo, p.18-20. 2014.

ANDRADE, J., LUCENA W. Educação financeira: uma análise de grupos acadêmicos. Economia e Gestão. Minas Gerais, v.18, 2018.

ANGELONI, M., Elementos intervenientes na tomada de decisão. Revista de Ciência e inovação. Brasília, v. 32, n. 1, p. 17-22, jan./abr. 2003.

ARRONDEL, L; DEBBICH, M. e SAVIGNAC, FRÉDÉRIQUE Financial Literacy and Financial Planning in France. Dezembro de 2013. Disponível em: http://ssrn.com/abstract $=2374363$. Acesso em: 25 mar. 2019.

BAZERMAN, M.; MOORE, D. Processo Decisório. 8. ed. São Paulo: Elsevier, 2014.

CERVO, A. L. e BERVIAN, P. A. Metodologia Científica: para uso dos estudantes universitários. 3.ed. São Paulo: McGraw-Hill do Brasil, 1983. 
DANCEY, C. P.; REIDY, J. Estatísticas sem matemática para psicologia. 5. ed. Porto Alegre: Artmed, 2013.

DONADIO, R., CAMPANARIO, M., RANGEL, A. O Papel da Alfabetização Financeira e do Cartão de Crédito no Endividamento dos Consumidores Brasileiros. Revista Brasileira de Marketing, São Paulo, v.18 n2, mai/jun. 2012.

ENEF (Brasil). $2^{\circ}$ Mapeamento Nacional das Iniciativas de Educação Financeira. 2018. Disponível em: <http://www.vidaedinheiro.gov.br/2-mapeamento/>. Acesso em: 11 mar. 2019.

ENEF (Brasil). Como implemetarDisponível em: http://www.vidaedinheiro.gov.br/como-implementar/. Acesso em: 16 abr. 2019.

FERNANDES, A., CANDIDO, J. Educação Financeira e Nível do Endividamento: Relato de Pesquisa entre os Estudantes de uma Instituição de Ensino da Cidade de São Paulo. Revista Eletronica de Gestão e Serviços V.5, n.2, jul./dez. 2014.

FERNANDES L. A.; GOMES, J. M. M. Relatório de pesquisa nas Ciências Sociais: Características e modalidades de investigação. ConTexto, Porto Alegre, v. 3, n. 4, 2003.

FIELD, Andy. Descobrindo a estatística usando SPSS. 2. ed. Porto Alegre: Artmed, 2009.

LELIS, M. G. Educação financeira e empreendedorismo. Centro de Produções Técnicas, 2006.

LUCCI, C., et. al. A influência da educação financeira nas decisões de consumo e investimento dos indivíduos. In: SEMINÁRIOS DE ADMINITRAÇÃO, 20, 2016, São Paulo, SP. Anais... São Paulo, 2006.

MAGRO,.D. B. et. al. O efeito da família no comportamento financeiro de adolescentes em escolas públicas. Revista de Contabilidade e Organizações. São Paulo, v. 12, mai/ dez. 2018.

MARCOLIN, S; ABRAHAN. Financial literacy research: current literature and future opportunities, 2006, Leura, 21-22 September.4. University of Wollongong Australia,

MARCONI, M. A.; LAKATOS, E. M. Fundamentos de metodologia científica. 5 ed. São Paulo: Atlas, 2003.

MARCONI, M. A.; LAKATOS, E. M. Fundamentos de metodologia científica. 7 ed. São Paulo: Atlas, 2010.

MELO, M. A. F. Educação financeira: educação financeira, poupança e investimento. 2016. Dissertação (Mestrado em Administração) - Fundação Getúlio Vargas. Rio de Janeiro, p. 15. 2016.

NETO, R.; CRUZ, G ANDRICH, G. A Importância do Valor do Dinheiro no Tempo e da Oportunidade no Sistema de Custeio Direto: Estudo de caso aplicado a um posto de combustível. Revista eletrônica dos cursos de Administração e Ciências Contábeis, Curitiba, v.I, jan/ jul 2009. 
PENG, T. M.; BARTHOLOMAE, S.; FOX, J. J.; CRAVENER, G. The impact of personal finance education delivered in high school and college courses. Journal of Family and Economic Issues, v. 28, n. 2, p. 265-284, 2007.

PUNHAGUI, B; VIEIRA S, FAVORETTO, R. Educação financeira e decisões de consumo: uma pesquisa com servidores públicos do Instituto Agronômico do Paraná. Revista de estudos contábeis, Londrina, v. VII p. 97-116, jan./jun. 2016.

ROGERS, P; FAVATO, V; SECURATO, J. Efeito educação financeira no processo de tomada de decisões em investimentos: um estudo a luz das finanças comportamentais. In: Anais.. São Paulo: ANPCONT, 2008.

SCHUMACHER, N. R.; GRESELE, W. D.; WALTER, S. A. Fatores do endividamento relacionado ao comportamento financeiro dos acadêmicos do Centro de Ciências Sociais Aplicadas da UNIOESTE, campus Marechal Cândido Rondon - PR. In: Encontro Ciêntífico de Ciências Sociais Aplicadas de Marechal Cândido Rondon: Tributação e Competitividade. XIII. 2018. Marechal Cândido Rondon, Paraná. Anais Eletrônico.Marechal Cândido Rondon, UNIOESTE. Disponível em: https://midas.unioeste.br/sgev/eventos/ccsamcr2018/anais.

SILVA, G. O. et al. Alfabetização financeira versus educação financeira: um estudo do comportamento de variáveis socioeconômicas e demográficas. Revista de Gestão, Finanças e Contabilidade, Salvador, v. 7, n.3, set/dez. 217.

SPC. Serviço de Proteção ao Crédito, 2018. Disponível em: https://www.spcbrasil.org.br/ wpimprensa/wp-content/uploads/2018/02/An\%C3\%A1lise-Endividamento-e-Impactos-nas-Financas-do-Consumidor.pdf. Acesso em: 15 mar. 2019.

VIEIRA, S., BATAGLIA, R., SEREIA, V., Educação financeira e decisões de consumo, investimento e poupança: uma análise dos alunos de uma universidade pública do norte do Paraná. Revista de administração da Unimep, v.IV, n.3, set/dez. 2011.

VITT, Lois A. Consumers' Financial Decisions and the Psychology of Values. Journal of Financial Service Professionals, Nov/2004.

WORTHINGTON, A. C. Predicting financial literacy in Australia. Financial Services Review, v. 15, n. 1, p. 59-79, 2006.

Submetido em: 18-11-2019

Aceito em: 30-2021 